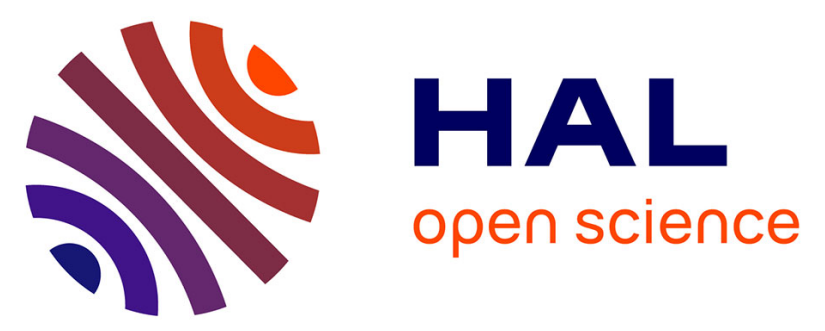

\title{
Modeling of an Energy-Efficient Wireless Sensor Network for Monitoring Restricted Areas in an Airport
}

\author{
Oluwadara J. Odeyinka, Michael C. C Ndinechi, Onyebuchi C. C Nosiri
}

\section{To cite this version:}

Oluwadara J. Odeyinka, Michael C. C Ndinechi, Onyebuchi C. C Nosiri. Modeling of an EnergyEfficient Wireless Sensor Network for Monitoring Restricted Areas in an Airport. International Journal of Scientific and Research Publications, 2019, 9 (11), pp.482-500. 10.29322/ijsrp.9.11.2019.p9567 . hal-03320250

\section{HAL Id: hal-03320250 \\ https://hal.science/hal-03320250}

Submitted on 15 Aug 2021

HAL is a multi-disciplinary open access archive for the deposit and dissemination of scientific research documents, whether they are published or not. The documents may come from teaching and research institutions in France or abroad, or from public or private research centers.
L'archive ouverte pluridisciplinaire HAL, est destinée au dépôt et à la diffusion de documents scientifiques de niveau recherche, publiés ou non, émanant des établissements d'enseignement et de recherche français ou étrangers, des laboratoires publics ou privés. 


\title{
Modeling of an Energy-Efficient Wireless Sensor Network for Monitoring Restricted Areas in an Airport
}

\author{
Oluwadara J. Odeyinka, Michael C. Ndinechi, Onyebuchi C. Nosiri \\ Department of Electrical and Electronic Engineering, Federal University of Technology, Owerri, Imo State, Nigeria.
}

DOI: 10.29322/IJSRP.9.11.2019.p9567

http://dx.doi.org/10.29322/IJSRP.9.11.2019.p9567

\begin{abstract}
Wireless Sensor Networks (WSNs) is an attractive solution for myriads of communication applications. The deployment of WSNs in restricted areas where battery replacement or recharging is difficult, demands that energy be sparingly utilized. In this study, a model of energy-efficient Wireless Sensor Networks (WSNs) for monitoring Aircraft Runway was developed to prolong the lifespan of the deployed network using a non-hierarchy and hierarchy based cluster configurations for two sampled Runways (R/W). A routing protocol which involved hierarchical data transfer along any shortest path to the Base Station (BS) was developed. The approach promotes rotation of Cluster Head $(\mathrm{CH})$ during every transmission round based on residual energy of nodes and proximity to Base Station. Simulations were carried out for 5000 transmission rounds in MATLAB environment for the non-hierarchical and other levels of hierarchy; six clusters and eighteen clusters. Results of simulation revealed the lifespan of the networks as: 3375 and 3750 rounds for the non-hierarchical configurations, 3912 and 4660 rounds for six clusters hierarchical configurations, while in the eighteen clusters hierarchical configurations the network lasted for 4434 and above the estimated 5000 rounds. Thus, the best solution in terms of network lifespan of the proposed model was obtainable in the highest possible cluster formed.
\end{abstract}

Index Terms- Energy-Efficiency, Hierarchy-Based Cluster, Network Lifespan, Residual Energy, Restricted Areas, Wireless Sensor Networks

\section{INTRODUCTION}

Wireless Sensor Networks (WSNs) consist of variable number of static or mobile nodes deployed across an area of interest to obtain, process and transmit relevant information. Wireless sensor node consist of several parts powered by battery [1], these includes: Sensing unit; this is capable of sensing temperature, humidity, visual, acoustic, location and many more. Micro-controller for processing the obtained data and a radio transceiver for transmitting the processed data to a Base Station (Sink) through a radio frequency channel. Sink node being a resourceful node having un-restricted communication, computational capability and additional energy source acts as an interface between wireless sensor networks and resource management center [2].The event being observed using WSNs may be static or dynamic depending on application scenario. Wireless Sensor Networks have been used in many applications such as: Home automation and security, military applications, boarder control, intelligence and reconnaissance surveillance [3], environmental applications such as fire forest detection, health application for patient monitoring, agricultural usage, vehicle tracking, inventory management, civil aviation and a host of other applications. In addition to the numerous usage of WSNs, it equally provides a bridge between the physical and virtual world and allows the ability to observe the previously unobserved at a fine resolution over large spatio-temporal scales [4].Therefore, the relevance of this work to Aviation Industry cannot be over emphasized as WSNs is envisioned to effectively monitor trespass on restricted areas. Depending on application scene, wireless sensor nodes can be randomly distributed or uniformly placed [5].Wireless Sensor Networks are envisioned to operate in an autonomous and unrestricted fashion and its deployment has the potential to overcome the limitations associated with wired sensor networks, perimeter fencing and security patrol team as a way of monitoring trespass on Airport restricted areas.

Due to the cost and small size of wireless sensor nodes, they have been equipped with small batteries having limited energy source thereby leading to a major energy constraint of wireless sensor nodes in terms of their lifespan. Sensing and processing of information by wireless sensor nodes consumes a minimal amount of energy but transmission and reception of information requires a significant amount of energy [6], [7]. Therefore, performing such energy consuming task reduces the lifespan of the entire network and consequently results into system meltdown. Since energy harvesting and battery replacement may not be feasible in certain environmental condition, there is a need to sparingly utilize the available energy. This could be achieved through the development of an energy-efficient data routing protocol to set up paths between wireless sensor nodes and the Base Station. The routing protocol must be such, that enhances load balancing and the path selection must be able to maximize the life-time of the network [8], [9]. 
Recently, many clustering algorithm have been developed with different protocols to prolong the lifespan of WSNs. Even though other techniques exist, clustering had proven to be one of the effective approaches used to save energy in WSNs [10], [11], [12]. Clustering is a method of organizing sensor nodes into different groups called clusters [12]; (a bunch of intra-connected sensor nodes). In each cluster, wireless sensor nodes are given different roles to play; cluster head, member node and gateway node. A Cluster Head $(\mathrm{CH})$ is a group leader in each cluster that receives sensed data from member nodes, aggregate and transmits to other Cluster Heads or Base Station. The role of member node is to sense data from the environment. Gateway nodes are nodes belonging to more than one cluster and their role is to transmit data between two clusters or between a Cluster Head and Base Station. Since clustering enhances Wireless Sensor Networks performance in terms of life-time through even distribution of role among wireless sensors and multi-hop transmission of data to the Base Station, its suitability in delivering improved intelligence, monitoring and surveillance system cannot be over-emphasized. Deploying WSNs; a technology that can provide smart environment, obtain accurate information in restricted environment may require that the network lifespan be prolonged. Thus, hierarchical clustering configurations would be adopted in this work to extend the lifespan of the model of energy-efficient WSNs proposed to monitor restricted areas in an Airport.

In WSNs, energy is one of the major issues which need to be carefully consumed by the sensor nodes to maximize the network life-time [13].To deploy a WSN that will monitor restricted areas in an Airport, it is expected that the network lifespan be prolonged. Since Wireless Sensor nodes are mostly powered with small batteries, absolute dependence on the battery which is the major power source not only limits the sensors lifespan, but also that of the deployed network. Hence there is a need for efficient design to extend the lifespan of the deployed network.

\section{REVIEW OF RELATED STUDIES}

Authors in [7] proposed the first known clustering protocol; Low Energy Adaptive Clustering Hierarchy (LEACH). The protocol was aimed to prolong the life-time of WSNs by reducing the energy consumption of sensor nodes. LEACH is hierarchical, probabilistic, distributed and single-hop protocol. Cluster formation is based on the strength of received signal, while cluster head act as default gateway to the Base Station.

Authors in [8] proposed an Energy Efficient Cluster Based Protocol (EECP) which is an extension of the LEACH protocol for heterogeneous network, some sensors of higher energy than the regular nodes which were called Gateway Nodes (GN) were embedded in the network. Gateway nodes change the method of sending the data to the Base Station. The main goal of the protocol was to efficiently maintain energy consumption of Wireless Sensor Networks (WSNs) and extend the lifespan of the network. EECP used a new distance-based probability scheme for the election of Cluster Head. Also, a few percentages of the nodes in EECP are more energy enriched than others, making EECP a bit different from LEACH. The proposed model achieved a longer lifespan, stable throughput in the network as compared to LEACH.

Authors in [10] proposed a new energy efficient data aggregation protocol in Wireless Sensor Networks. A homogenous WSN consisting of $\mathrm{N}$ sensor nodes that are uniformly and randomly distributed within an area of $\mathrm{L}$ by $\mathrm{W}$ square meter and the sink node located at $(\mathrm{L}+\mathrm{W}, \mathrm{W} / 2)$ coordinates. The key ideal behind the algorithm was to recursively divide the sensor network into four partitions symmetrical about a centered node. Furthermore, a set of Cluster Heads in the middle of each partition were defined to aggregate data from cluster members and transmit these data to Cluster Heads in the next hierarchical level. The new algorithm adopted the concept of hierarchical clustering which prevents Cluster Heads from sending their data for long distances and thus the energy consumption of the sensor nodes was significantly reduced. The algorithm focused on avoiding the overhead of dynamic clustering, reducing the transmission path between sensor nodes and Cluster Head nodes and minimizing the direct communication between the sink node and Cluster Heads. Simulation results showed that the proposed algorithm achieved better performance in comparison with the LEACH-C algorithm in terms of energy consumption, network lifespan and number of dead nodes.

Authors in [15] opined a multi-hop clustering routing protocol. The scheme utilized a multi-level hierarchical data gathering sensor network architecture. At the lowest level, wireless sensor nodes send data to the Cluster Head, and Cluster Head sends data to the gateway nodes. The gateway nodes, which formed the next level of hierarchy, were programmed to communicate with the Sink located outside the network field. Cluster Heads were selected based on LEACH protocol. As soon as a Cluster Head is formed, it selects a gateway node which lies closest to it. The implementation of gateway nodes enhanced the network in terms of minimum energy consumption and longer network life as compared to LEACH.

Authors in [16] introduced a new method of cluster heads selection and cluster formation algorithm. 100 sensor nodes were assumed to be deployed in a 100 by 100 square-meter field and Base Station at $(50,350)$ coordinates. The algorithm partitioned the sensor field into different clusters and elects a node as the Cluster Head for each cluster. Each node within the cluster sends its data to the 
Cluster Head with single hop transmission and Cluster Heads receive, aggregate the data and transmit to the Base Station through multi-hop transmission. The adopted method conserves energy of sensor nodes in the clusters. Simulation result revealed that the algorithm conserves more energy than LEACH and TL-LEACH protocol due to short range data transmission of sensor nodes and election of Cluster Heads based on residual energy of each node.

An Event Driven Hierarchical cluster-based routing protocol for Wireless Sensor Networks which is an energy efficient hierarchical routing technique in which Cluster Heads are selected based on the prediction of transmission energy through shortest possible distance to the Base Station for transmitting the event driven information was proposed by authors in [17]. In this, cluster of the sensor nodes were geographically created, Cluster Head role were rotated and the optimization of the $\mathrm{CH}$ selection by the help of energy prediction used for transmission in every rounds of simulation. When event occurs, $\mathrm{CH}$ aggregates event data before transmitting it to the Base Station. The important features which include: Cluster formation and rotation, Cluster Head election and rotation, and cluster optimization of the proposed event driven hierarchical routing technique in transmitting event driven data to the Base Station were analyzed. The analysis revealed that energy efficiency of WSNs can be further improved by using the event driven hierarchical routing technique. In the algorithm, the clusters were geographically formed into different sizes to see how it could affect the network lifespan of WSNs. With energy awareness and event driven protocol, the proposed protocol, which utilizes the prediction of least transmission energy through the shortest possible path to send data to the Base Station proved that it offers more reduced energy consumption and increases the lifespan of the WSN. From the result, the proposed protocol shows better performance for second level of hierarchy than first level hierarchical routing protocol and non-hierarchical technique.

\section{SIMULATION TOOL AND PARAMETERS}

\section{A. TOOL}

The model of energy-efficient wireless sensor networks developed in this research work is validated with simulation in MATLAB environment. With regards to simulating WSNs, MATLAB provides communication toolbox set to building the hardware architecture of transmitting nodes, modeling the communication channel and receiving node architecture.

\section{B. WIRELESS SENSOR NODES}

The wireless sensor nodes in the deployed networks are homogeneous in nature (have the same capacity in terms of computational capability and power). The initial energy of all the nodes are set to 10nJ, each has a unique identity and are evenly distributed along the perimeter of the experimental region.

\section{SINK NODE}

The Sink node represents the Base Station which is a resourceful node with unlimited capacity in terms of computational capability and power. The data routed from wireless sensor nodes are received at the Base Station through the Cluster Heads. The Sink node serves as the data management center. The detailed information such as location and identity of wireless sensor nodes, energy content of nodes and other information in the deployed network are controlled at the Sink node. In the MATLAB simulation environment, the location of the Sink node is set to $(-30,-10)$ coordinate of the experimental region. Other simulation parameters are listed on Table 1 .

\section{METHODOLOGY}

Sensor nodes are evenly distributed over the entire perimeter of the experimental region. Clusters are thereafter geographically formed based on equal division of the perimeter to be monitored. Having formed the first non-hierarchical cluster (a single cluster), other levels of hierarchy; level six and level eighteen are formed. All clusters contain equal numbers of sensor nodes at each level of formation. Cluster head $(\mathrm{CH})$ selection within each cluster formed at all levels is done by election of a node that requires the least transmission energy for a particular transmission round, and is rotated among the sensor nodes of each cluster at every transmission round. At the beginning of every transmission round, new energy estimation is carried out to determine the $\mathrm{CH}$ to be elected next, ensuring significant reduction in nodes energy consumption and increase the lifespan of the network. A hierarchical routing protocol is developed in phases after even distribution of the sensor nodes along the experimental regions perimeter as follows:

Phase one: Clusters are formed geographically around the runways perimeter.

Phase two: Cluster head $(\mathrm{CH})$ selection is made in each cluster formed. This phase is based on energy prediction technique using the first order radio energy model [18].

Phase three: In this phase, data collected by the CHs from the sensor nodes within their clusters are gathered.

Phase four: Here, all data collected by the CHs are further transmitted to the BS or Sink. A comparison of the network lifespan of the non-hierarchical and the various hierarchical configurations would be carried out for the perimeter surveillance model. 
An investigation into the optimal level of hierarchy, that is; the effect of increasing the cluster size to six and eighteen on the network lifespan would be determined. Finally, the result would be validated by simulating in MATLAB environment.

\section{A. SENSOR NODES DEPLOYMENT}

A total of 306 nodes were uniformly deployed around the perimeter of an Airport Aircraft Runway (R/W) with dimensions: 3000m by 60m (Port Harcourt International Airport Aircraft Runway) [19] and 2700m by 45m (Sam Mbakwe Airport Aircraft Runway) [20]. Cluster head selection was predicted for 5000 rounds for the non-hierarchical and the hierarchical configurations. Simulation was thereafter executed in MATLAB environment, while Figures 1, 2, 3, 4, 5 and 6 illustrate the various deployments. The following assumptions are made:

1. The proposed area of interest is rectangular shaped with dimension (L by B) square meter.

2. All nodes are homogeneous; having equal capacity in terms of computation, communication and power, in nature and static.

3. All the nodes have the same initial energy.

4. RN transmits directly to their respective $\mathrm{CHs}$ within a particular cluster.

5. CHs transmit data to the Sink by multi-hop routing.

6. The Sink is located at the origin $(-30,-10)$ of the experimental region and has the information about the identity and location of each node.

7. The Communication link between the nodes is symmetrical.

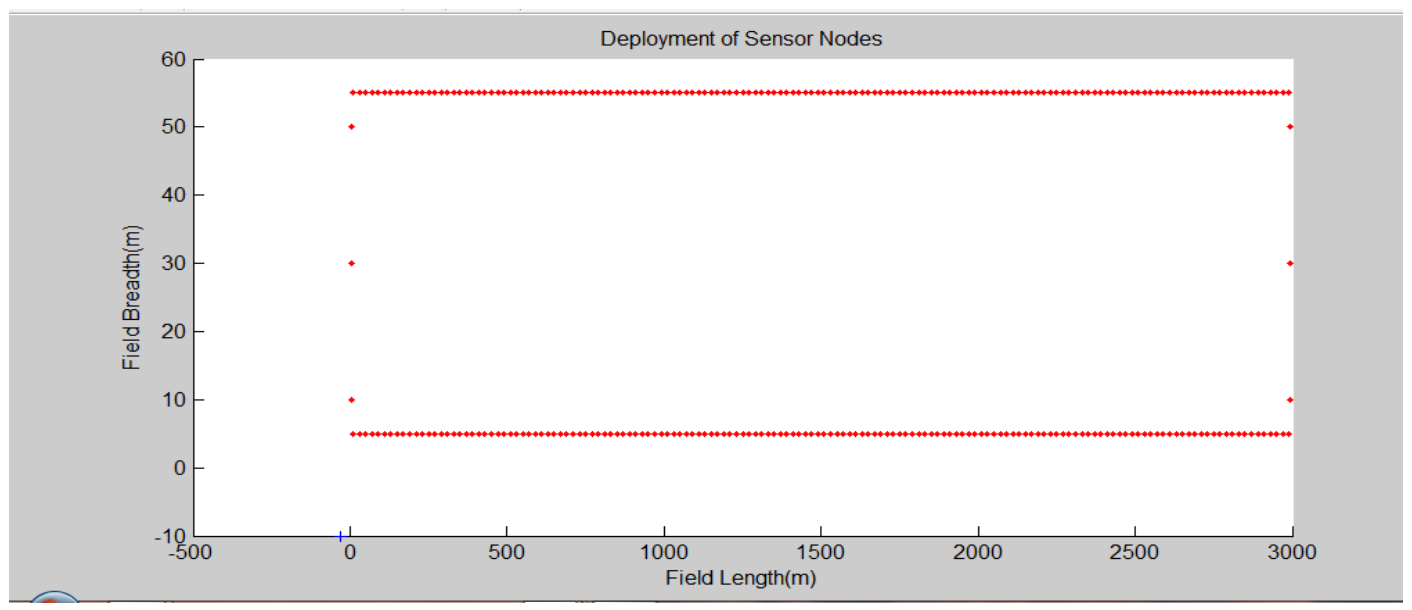

Figure1: Sensor Nodes Deployment (Non-hierarchical) for 3000m by 60m R/W 


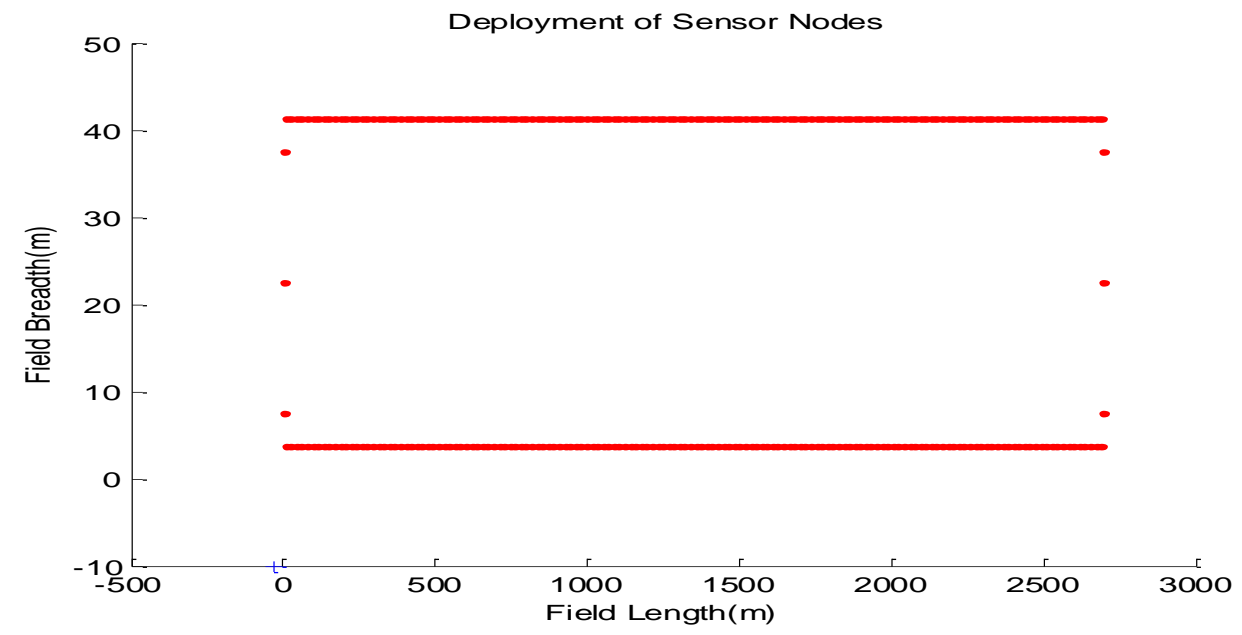

Figure 2: Sensor Nodes Deployment (Non-hierarchical) for 2700m by $45 \mathrm{~m} \mathrm{R} / \mathrm{W}$

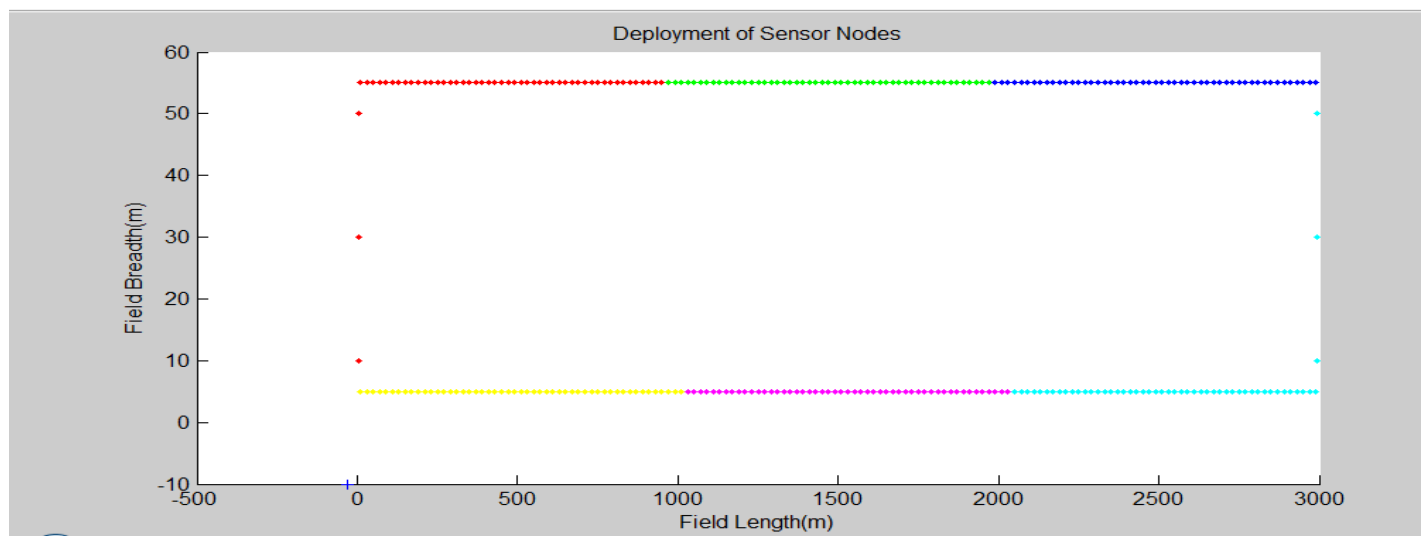

Figure 3: Sensor Nodes Deployment (6 clusters) for $3000 \mathrm{~m}$ by $60 \mathrm{~m} \mathrm{R} / \mathrm{W}$ 


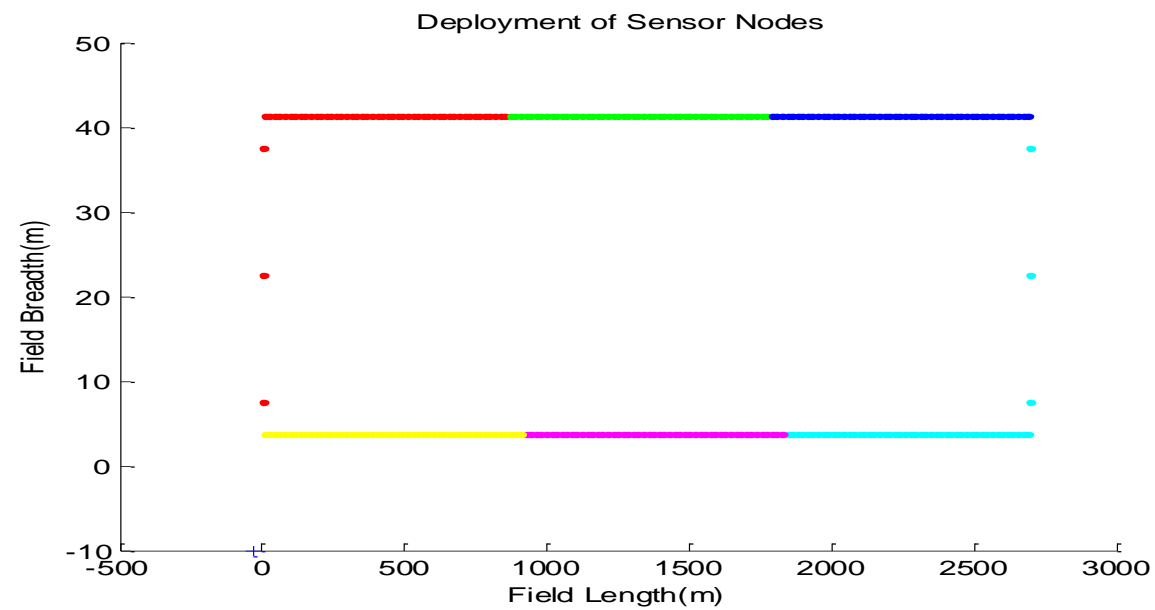

Figure 4: Sensor Nodes Deployment (6 clusters) for $2700 \mathrm{~m}$ by $45 \mathrm{~m} \mathrm{R} / \mathrm{W}$

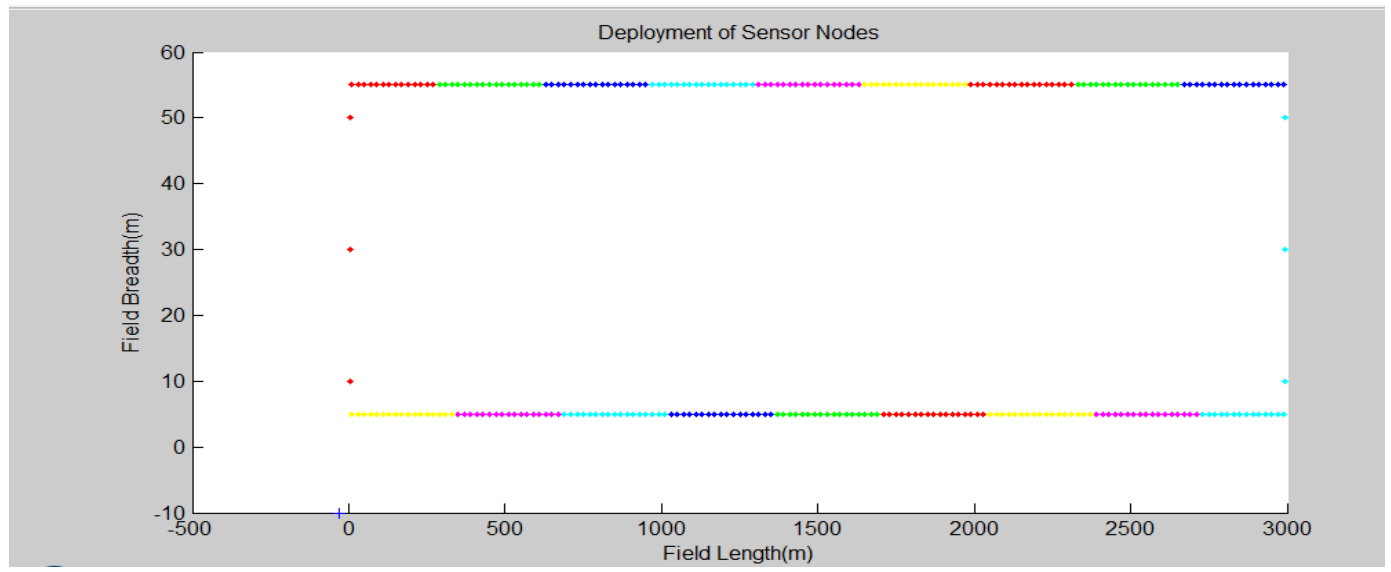

Figure 5: Sensor Nodes Deployment (18 clusters) for $3000 \mathrm{~m}$ by $60 \mathrm{~m} \mathrm{R} / \mathrm{W}$

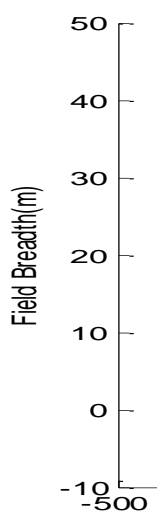

Deployment of Sensor Nodes

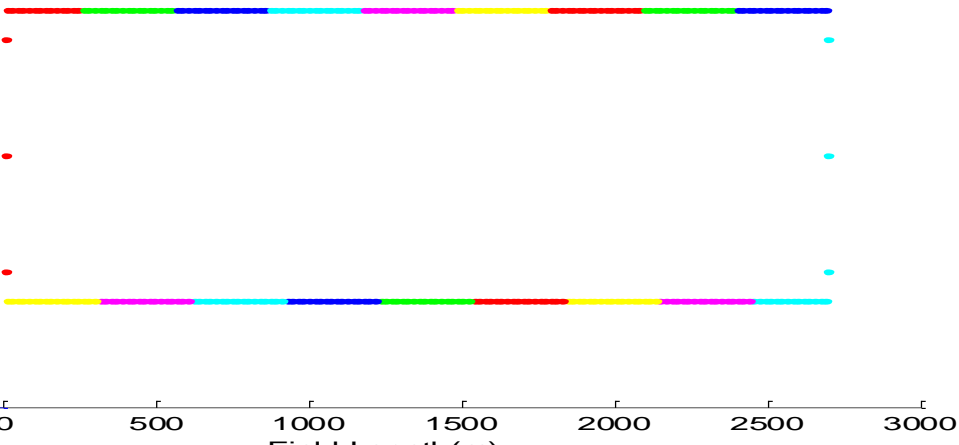

Figure 6: Sensor Nodes Deployment (18 clusters) for $2700 \mathrm{~m}$ by $45 \mathrm{~m} \mathrm{R} / \mathrm{W}$ 


\section{B. ENERGY MODEL FOR SENSOR NODES COMMUNICATION}

In this work, a simple model for the radio hardware energy dissipation where the transmitter dissipates energy to run the radio electronics and the power amplifier, and the receiver dissipates energy to run the radio electronics; $\mathrm{E}_{\mathrm{TX}(\text { elect) }}$ and $\mathrm{E}_{\mathrm{RX}(\mathrm{elect})}$ is set to $50 \mathrm{~nJ} / \mathrm{bit}$ while $\epsilon_{a m p}$ is set to $100 \mathrm{pJ} / \mathrm{bit} / \mathrm{m}^{2}$ for the transmit amplifier to achieve an acceptable $\mathrm{E}_{\mathrm{b}} / \mathrm{N}_{\mathrm{o}}$ (energy per bit over noise spectral density) [18]. The cost to transmit a message depends on the distance between the transmitter and receiver. Thus, to transmit a $k$-bit message a distance $d$, the radio expends energy [18]:

$$
\mathrm{E}_{\mathrm{TX}}(\mathrm{k}, \mathrm{d})=\mathrm{k} * \mathrm{E}_{\mathrm{TX}(\text { elec })}+\mathrm{k} * \mathrm{~d}^{2} * \epsilon_{\mathrm{amp}}
$$

$\mathrm{E}_{\mathrm{TX}}(\mathrm{k}, \mathrm{d})$ is the energy required to transmit a $\mathrm{k}$ bit data through a distance $\mathrm{d}$. $\mathrm{E}_{\mathrm{TX}(\mathrm{elect})}$ is the transmitter electronics energy, $\in_{a m p}$ is the free space transmit amplifier.

To receive this message, the radio expends energy [18]:

$\mathrm{E}_{\mathrm{RX}}(\mathrm{k})=\mathrm{k} * \mathrm{E}_{\mathrm{RX}(\text { elect })}$

$\mathrm{k}$ is the size of the data in bit, and $\mathrm{E}_{\mathrm{RX}(\text { elect) }}$ is the receiver electronics energy. Figure 7 illustrates the communication model.

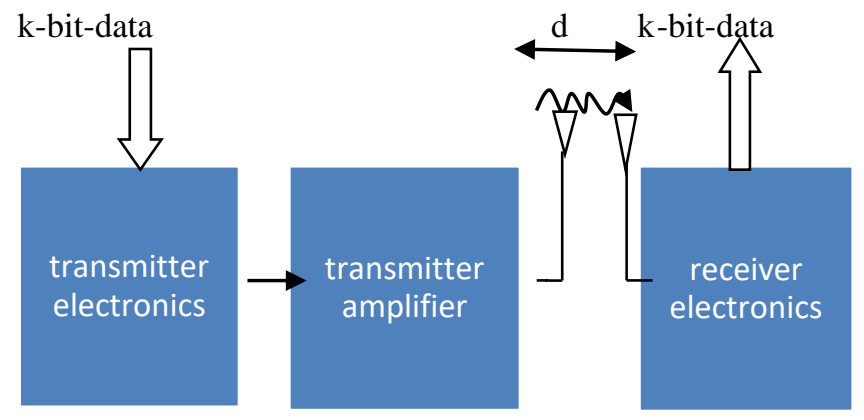

Figure 7: Block diagram of communication model

Where 'd' is the distance between the source and Sink. Using a direct communication protocol, each sensor sends its data directly to the Base Station. If the Base Station is far away from the nodes, direct communication will require a large amount of transmit power from each node. This will quickly drain the battery of the nodes and in turn reduces the network lifespan. Nodes route their packet to the Base Station through intermediate nodes. Thus nodes act as routers for other nodes in addition to sensing the environment. The existing routing protocol considers the energy of the transmitter and neglects the energy dissipation of the receiver in determining the routes in equation 1. Depending on the relative cost of the transmit amplifier and the radio electronics, the total energy expended in the system might be greater in multi-hop transmission than direct transmission to the Base Station. Assume that there is ' $n$ ' number of intermediate nodes (hops) to reach at the destination and also each adjacent node is differentiated with distance ' $r$ ' between them. So, the total distance between sources to BS is $(\mathrm{n} * \mathrm{~d})$, and for a single hop from one $\mathrm{CH}$ to another $\mathrm{CH}$, distance ' $\mathrm{d}$ ' in equation 1 is taken as ' $\mathrm{r}$ ' thereby reducing the energy to be dissipated by a $\mathrm{CH}$ to transmit data through a distance ' $\mathrm{d}$ ' in a single hop to the BS. Considering the energy expenditure at each node while transmitting a single k-bit message from source node $\mathrm{N}$ to Base Station, a node located with a distance from the Base Station using the direct communication approach is in equation 1 and 2. From equation 1,

$E_{\text {direct }}=E_{\mathrm{TX}}(\mathrm{k}, \mathrm{d} ; \mathrm{d}=\mathrm{n} * \mathrm{r})$

$\mathrm{E}_{\mathrm{TX}}=\mathrm{E}_{\mathrm{TX}(\text { elec })} * \mathrm{k}+\epsilon_{\mathrm{amp}} * \mathrm{k}(\mathrm{n} * \mathrm{r})^{2}$

$\mathrm{E}_{\mathrm{TX}}=\mathrm{E}_{\mathrm{TX}(\text { elec })} * \mathrm{k}+\epsilon_{\mathrm{amp}} * \mathrm{k}\left(\mathrm{n}^{2} * \mathrm{r}^{2}\right)$ 
Packet passes through the $\mathrm{n}$ intermediate nodes to reach at the destination means it required $\mathrm{n}$ times transmit and $\mathrm{n}-1$ times receive from equation (2);

$\mathrm{E}_{\mathrm{RX}}=(\mathrm{n}-1) \mathrm{E}_{\mathrm{RX}} * \mathrm{k}$

So total energy expended to reach at the destination is:

$\mathrm{E}=\mathrm{E}_{\mathrm{TX}(\text { elect })} * \mathrm{k}+\epsilon_{\mathrm{amp}} * \mathrm{k}\left(\mathrm{n}^{2} * \mathrm{r}^{2}\right)+(\mathrm{n}-1) \mathrm{E}_{\mathrm{RX}}$

$\mathrm{E}=\mathrm{k}\left(\mathrm{E}_{\mathrm{TX}(\text { elect })}+\epsilon_{\mathrm{amp}}\left(\mathrm{n}^{2} * \mathrm{r}^{2}\right)+(\mathrm{n}-1) \mathrm{E}_{\mathrm{RX}(\text { elect })}\right.$

In the direct communication with the Base Station, the energy expended is

$\mathrm{E}=\mathrm{E}_{\mathrm{TX}}+\mathrm{E}_{\mathrm{RX}}$

$\mathrm{E}=\mathrm{E}_{\mathrm{TX}(\text { elect })} * \mathrm{k}+\mathrm{k} * \mathrm{~d}^{2} * \epsilon_{\mathrm{amp}}+\mathrm{E}_{\mathrm{RX}(\text { elect })} * \mathrm{k}$

\section{PROPOSED AIRCRAFT RUNWAY ROUTING PROTOCOL}

The proposed Aircraft Runway protocol is based on hierarchical data transfer along any shortest path through the cluster heads to the Base Station located at the point $(-30,-10)$ coordinates of the Aircraft Runway. Cluster head selection is based on the energy levels of the nodes and Sensor nodes are uniformly distributed over the entire perimeter of an Aircraft Runway. Non hierarchybased cluster (uniform distribution of nodes around the runway perimeter) and hierarchy-based cluster (segmentation of the runway perimeter to the maximum possible cluster size) are formed. The BS (sink) starts the process by asking nodes to form clusters. The $\mathrm{CH}$ election phase proceeds after the cluster formation phase. The selection of $\mathrm{CH}(\mathrm{s})$ within each cluster formed is carried out by electing a node that requires least transmission energy to the BS to be the $\mathrm{CH}$ for a particular transmission round. Due to draining activities being constrained on a Cluster Head during data aggregation and transfer phase, Cluster Head role is rotated among the sensor nodes of each cluster at every transmission round. A completely new estimation of energy is carried out at the beginning of every transmission round to elect a new $\mathrm{CH}$ for the cluster and thereby energy wastage is being reduced to its minimum and utilization of each node's energy is being maximized to ensure a prolonged network lifetime. The approach promotes the rotation of $\mathrm{CH}$ role among the nodes of the cluster in order to prolong nodes lifespan.

The hierarchy-based, energy-efficient routing protocol developed for an Airport Aircraft Runway is summarized as follows:

1. Geographical node deployment and cluster formation phase.

2. Selection of cluster head in each cluster formed.

3. Data aggregation phase which involves the gathering of collected data by the cluster head from the sensor nodes within its cluster, the data aggregation phase is based on energy prediction technique using the first order radio energy model [8]. This is described thus:

a. The initial energy, $\mathrm{E}_{\mathrm{in}}$ of each node $(\mathrm{RN}$ or $\mathrm{CH})$ is measured.

b. The distance, $\mathrm{d}_{\mathrm{n}}$ between each regular node $(\mathrm{RN})$ and the $\mathrm{CH}$, where, $n=1,2,3, \ldots$ is measured.

c. Energy required by each node for transmission within the cluster is estimated using the formula:

$\mathrm{E}_{\mathrm{rn}}=\epsilon_{\mathrm{amp}} * \mathrm{k} * \mathrm{~d}_{\mathrm{n}}{ }^{2}$

Where $\mathrm{E}_{\mathrm{rn}}$ is the energy required by regular nodes for intra-cluster communication, $\epsilon_{a m p}$ is the free space transmit amplifier and $d_{n}$ is the distance between regular node and $\mathrm{CH}$. 
d. The maximum energy after the subsequent transmission round for each node (RN) is estimated and selection of $\mathrm{CH}$ is done using the formula:

$\mathrm{E}_{\mathrm{rn}}(\max )=\mathrm{E}_{\mathrm{in}}-\left(\epsilon_{\mathrm{amp}} * \mathrm{k} * \mathrm{~d}_{\mathrm{n}}^{2}\right)$

$\mathrm{E}_{\mathrm{rn}}(\max )$ is maximum energy of regular node, $\mathrm{E}_{\mathrm{in}}$ is the initial energy of nodes, $\boldsymbol{\epsilon}_{\boldsymbol{a} \boldsymbol{m} \boldsymbol{p}}$ is the free space transmit amplifier, $\mathrm{k}$ is the data size in bit and $\mathrm{d}_{\mathrm{n}}$ is the distance between regular node and $\mathrm{CH}$, and the next $\mathrm{CH}$ selection will take place after the completion of the current round.

4. Data transmission phase which involves the transfer of all data from the nearest Cluster Head(s) to the BS.

The performance of the proposed Airport Aircraft Runway surveillance was evaluated by using the lifespan of network, that is, number of Active Sensor Nodes versus Number of Rounds. Figure 8 illustrates with flow chart, the proposed Aircraft Runway Routing Protocol. The energy model proposed by [8] was used to verify the operation of the proposed network while the numerical correctness of the model was validated using MATLAB tool box.

TABLE 1: SIMULATION PARAMETERS

\begin{tabular}{ll}
\hline Parameters & Quantity \\
\hline Total number of nodes & 306 \\
\hline Initial sensor node energy $(\mathrm{J})$ & 2000 \\
\hline Packet size (bits) & 5000 \\
\hline Rounds & 1 \\
\hline Data period (seconds) & 50 \\
\hline Transmit electronic energy $(\mathrm{nJ})$ & 50 \\
\hline Receive electronic energy $(\mathrm{nJ})$ & 100 \\
\hline Transmit power amplifier energy (pJ) & $(-30,-10)$ \\
\hline Base station coordinate & \\
\hline
\end{tabular}




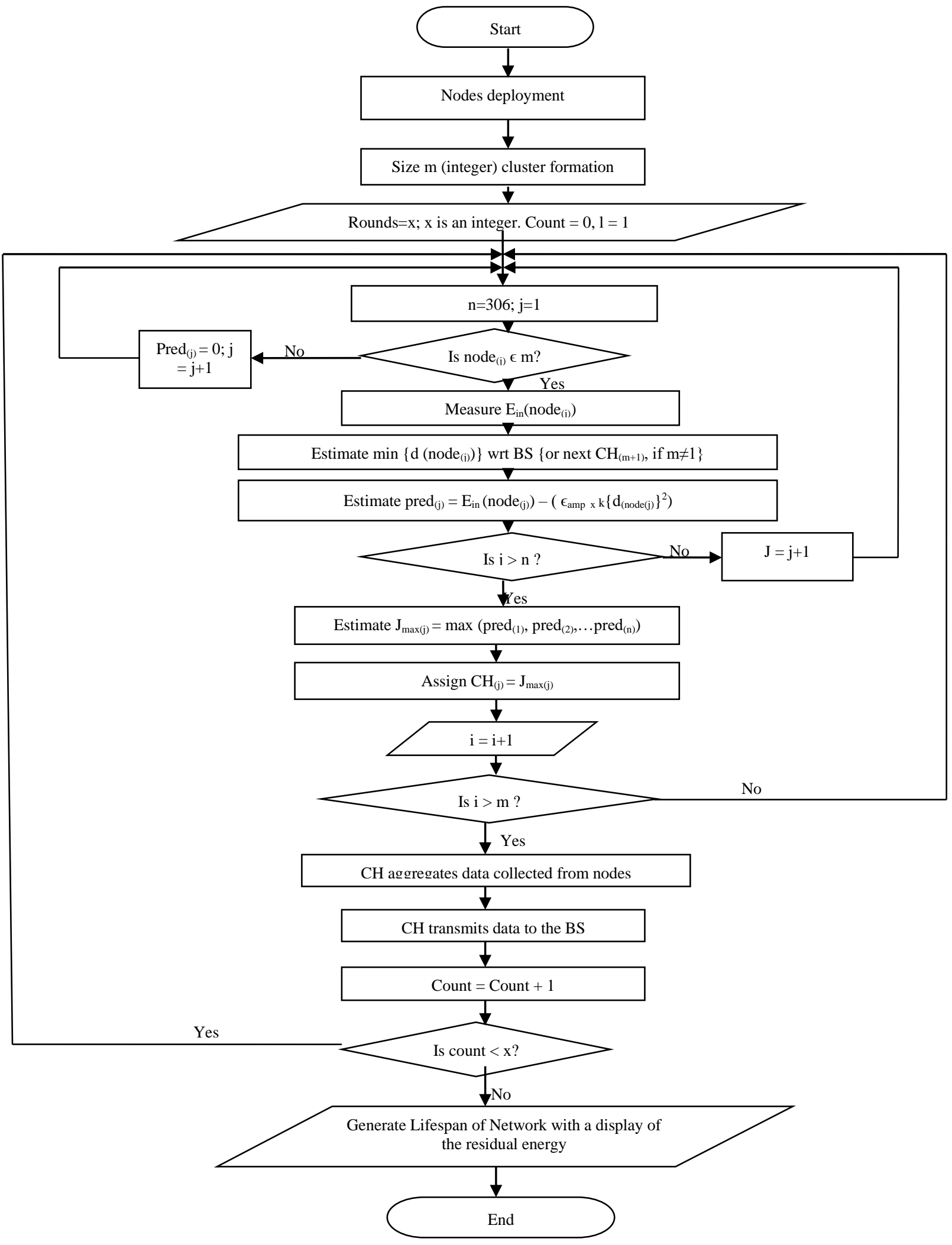

Figure 8: Flowchart of Proposed Aircraft Runway Routing Protocol 


\section{RESULTS AND DISCUSSION}

\section{A. RESULTS}

The simulation results were realized in MATLAB environment and the simulation condition was selected for the perimeter of two different Aircraft Runways, with dimensions; $3000 \mathrm{~m}$ by $60 \mathrm{~m} \mathrm{[19]} \mathrm{and} \mathrm{2700m} \mathrm{by} 45 \mathrm{~m}$ [20]. The implemented simulation parameters are shown on Table 1.

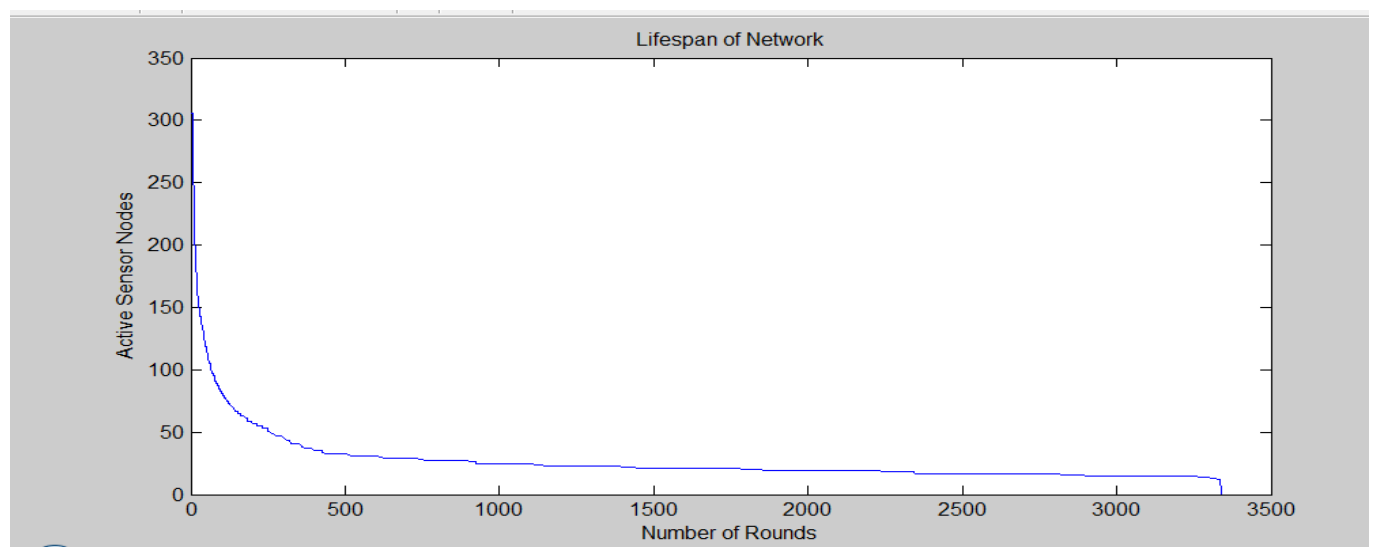

Figure 9: Lifespan of non-hierarchical network of $3000 \mathrm{~m}$ by $60 \mathrm{~m} \mathrm{R} / \mathrm{W}$

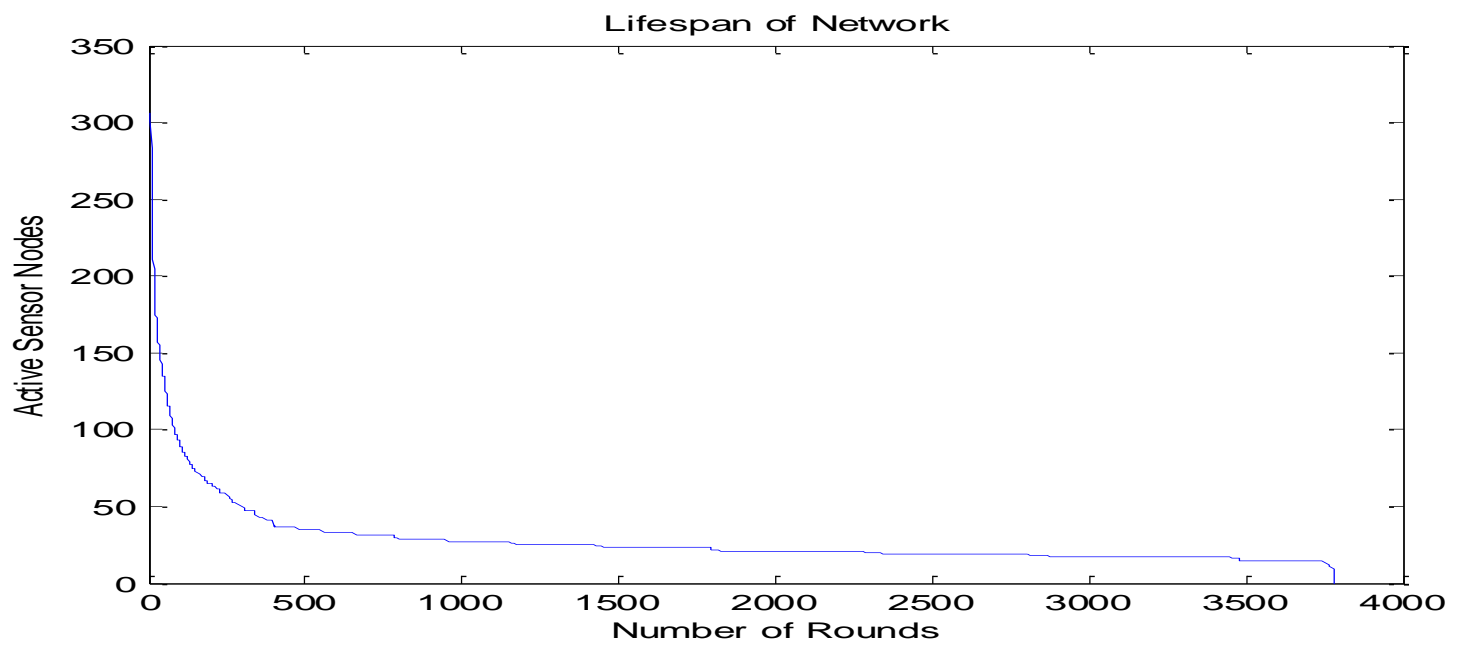

Figure 10: Lifespan of non-hierarchical network of $2700 \mathrm{~m}$ by $45 \mathrm{~m} \mathrm{R} / \mathrm{W}$ 


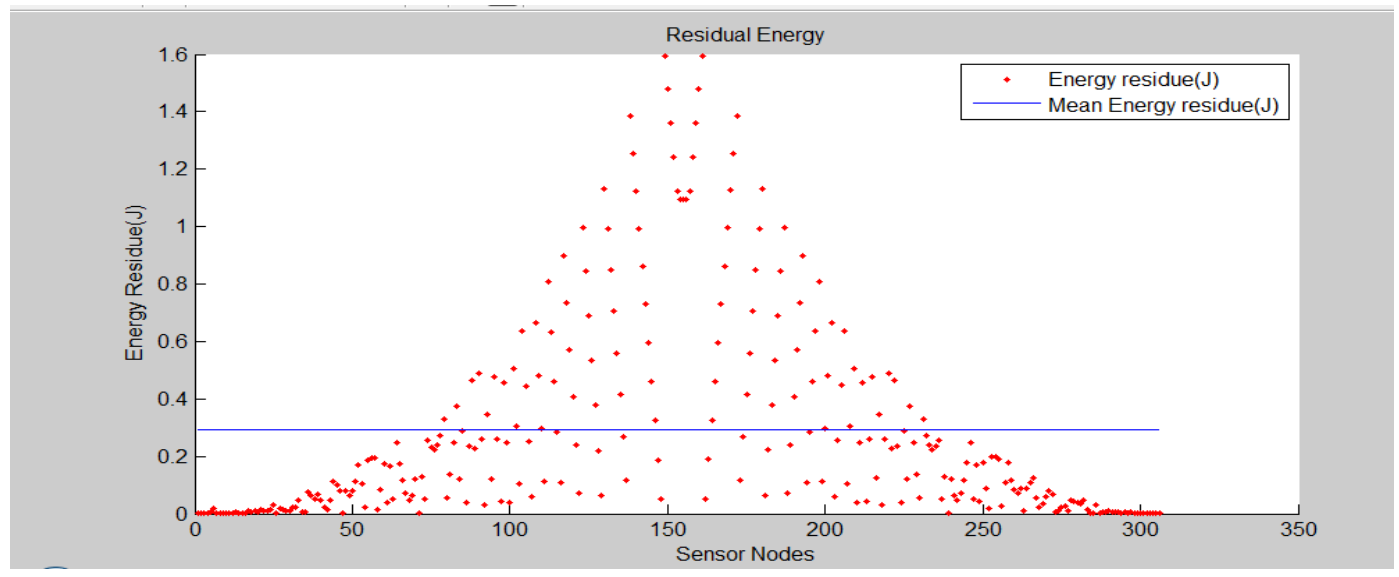

Figure 11: Residual Energy of non-hierarchical network of $3000 \mathrm{~m}$ by $60 \mathrm{~m} \mathrm{R} / \mathrm{W}$

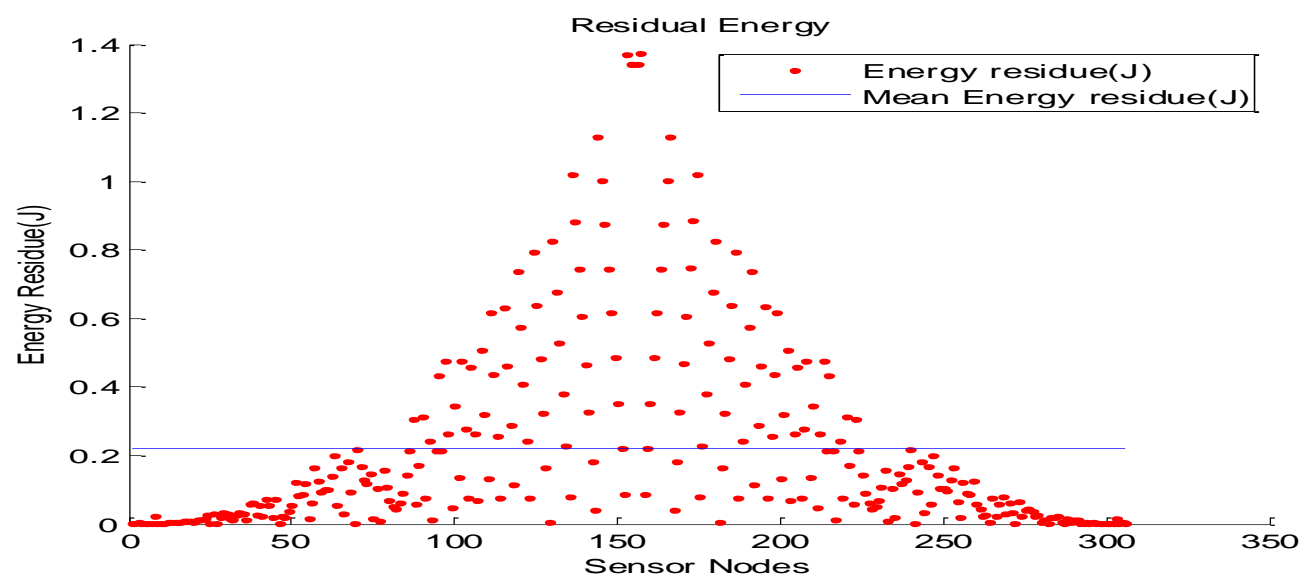

Figure 12: Residual Energy of non-hierarchical Network of $2700 \mathrm{~m}$ by $45 \mathrm{~m}$ R/W

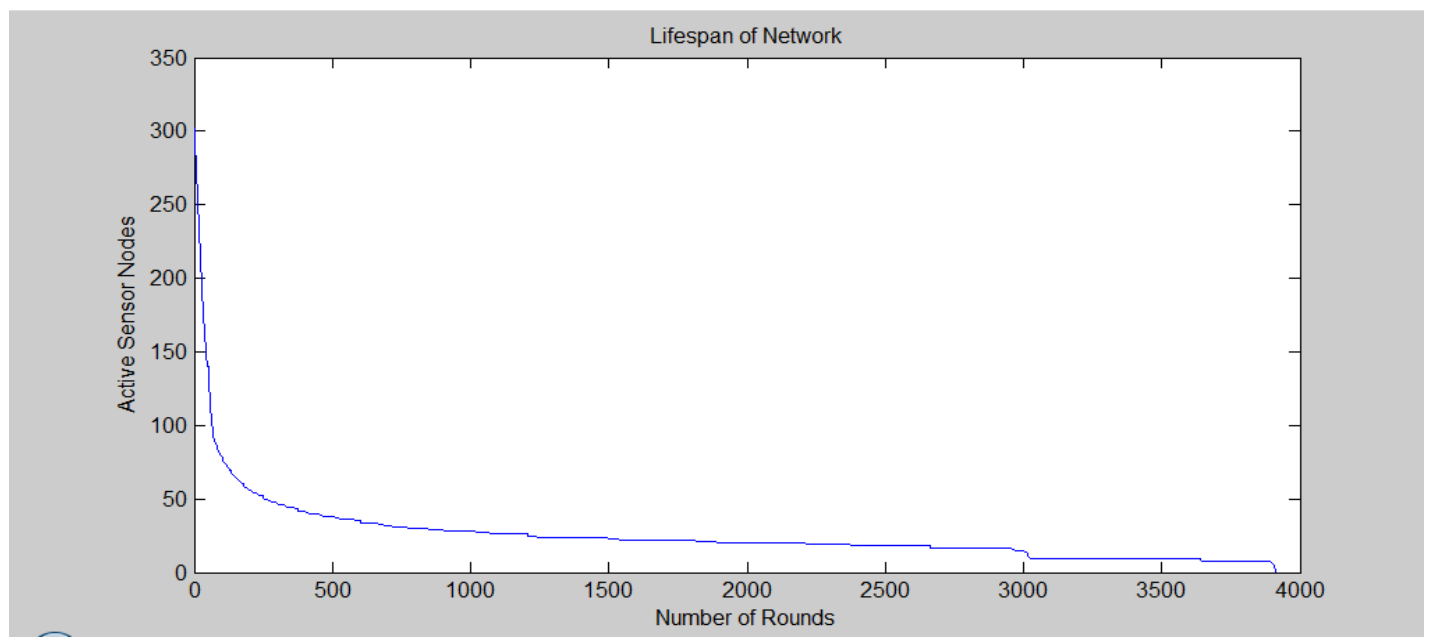

Figure 13: Lifespan of hierarchical (6 Clusters) Network of $3000 \mathrm{~m}$ by $60 \mathrm{~m} \mathrm{R} / \mathrm{W}$ 


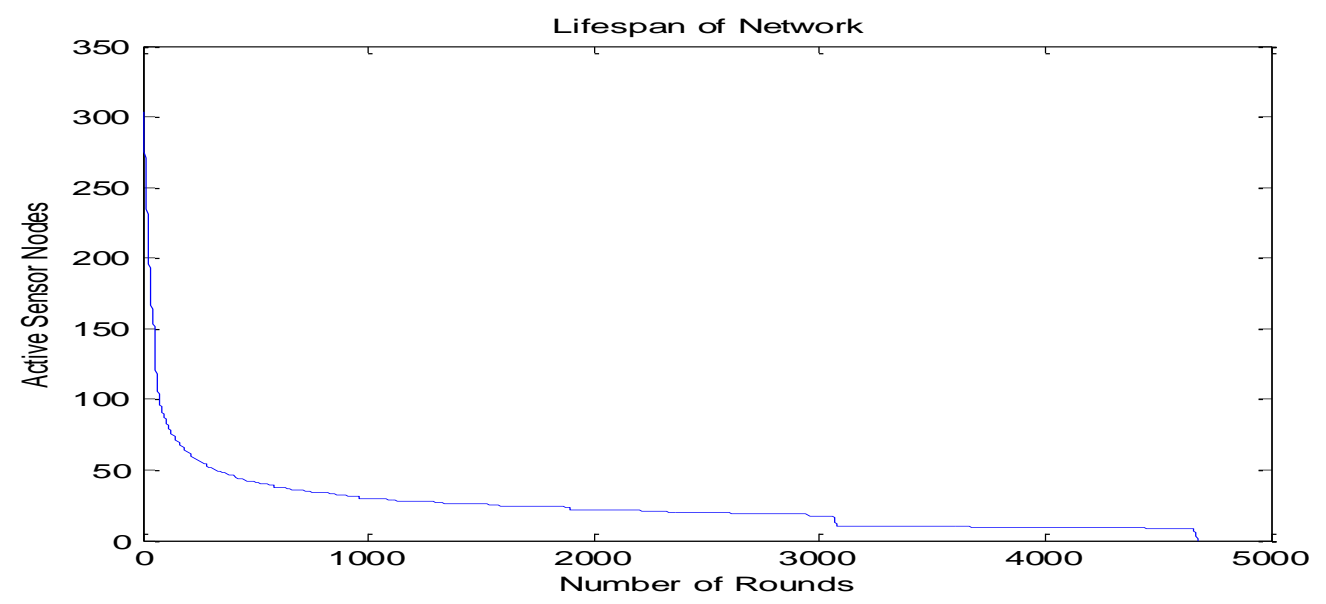

Figure 14: Lifespan of hierarchical (6 Clusters) Network of $2700 \mathrm{~m}$ by $45 \mathrm{~m} \mathrm{R} / \mathrm{W}$

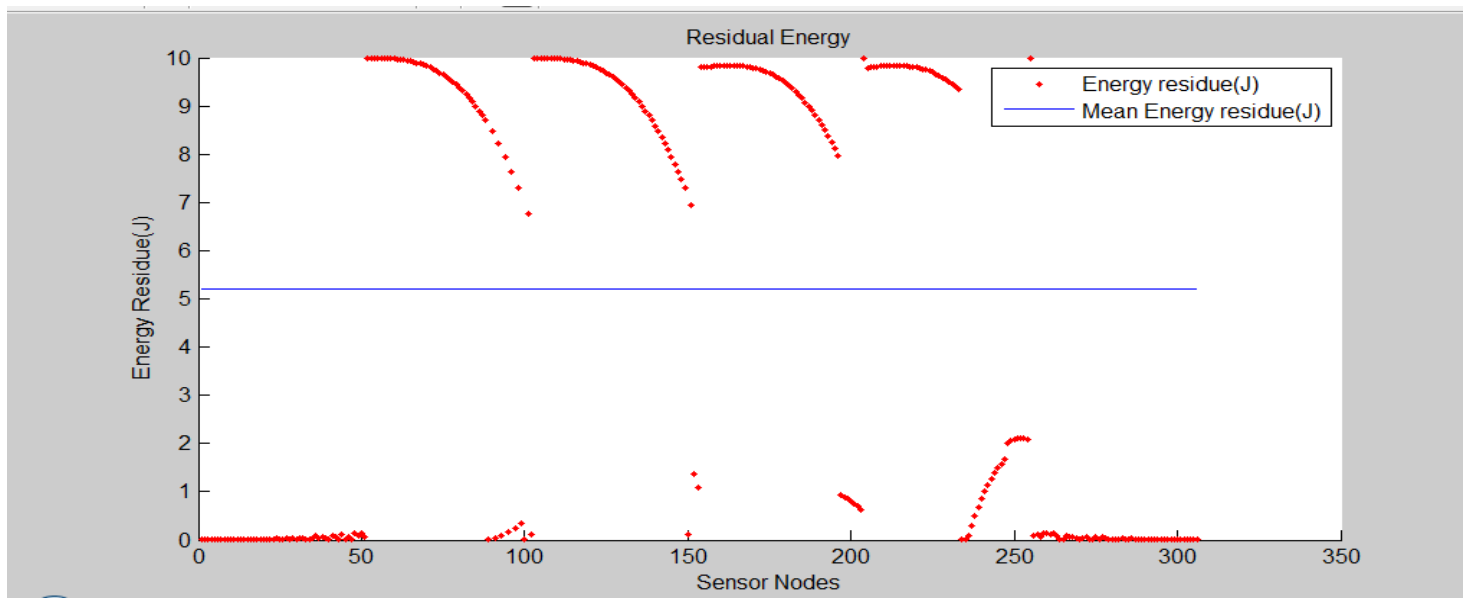

Figure 15: Residual Energy of hierarchical (6 Clusters) Network of $3000 \mathrm{~m}$ by $60 \mathrm{~m} \mathrm{R} / \mathrm{W}$

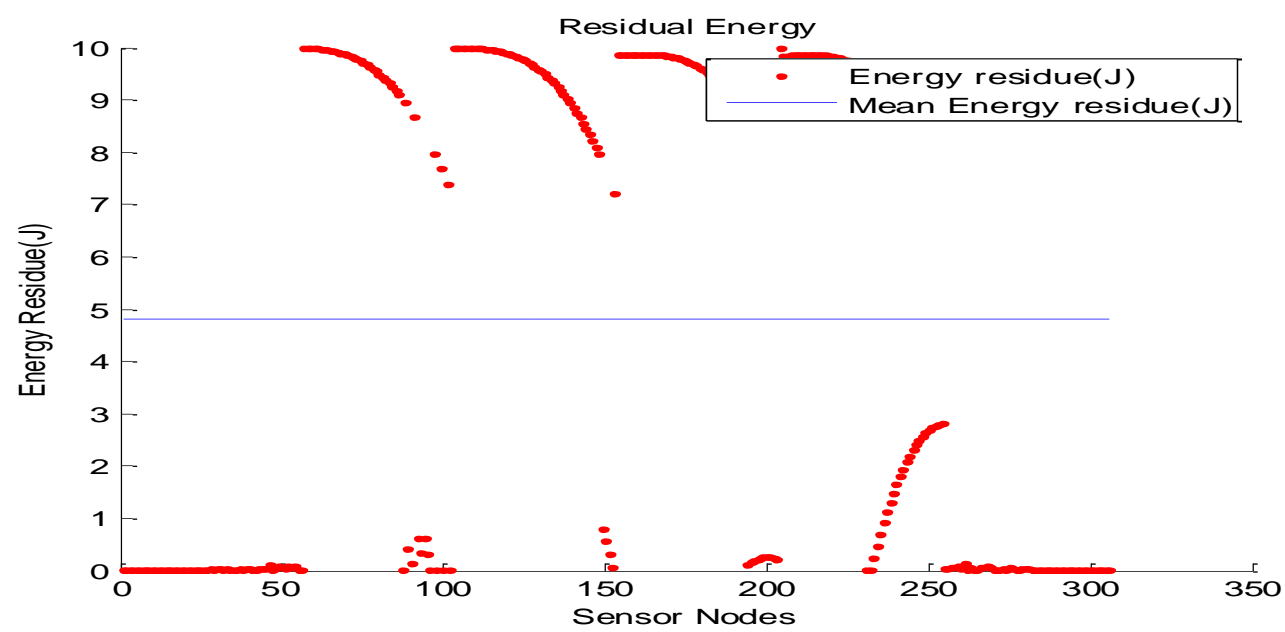

Figure 16: Residual Energy of hierarchical (6 Clusters) Network of $2700 \mathrm{~m}$ by $45 \mathrm{~m} \mathrm{R} / \mathrm{W}$ 


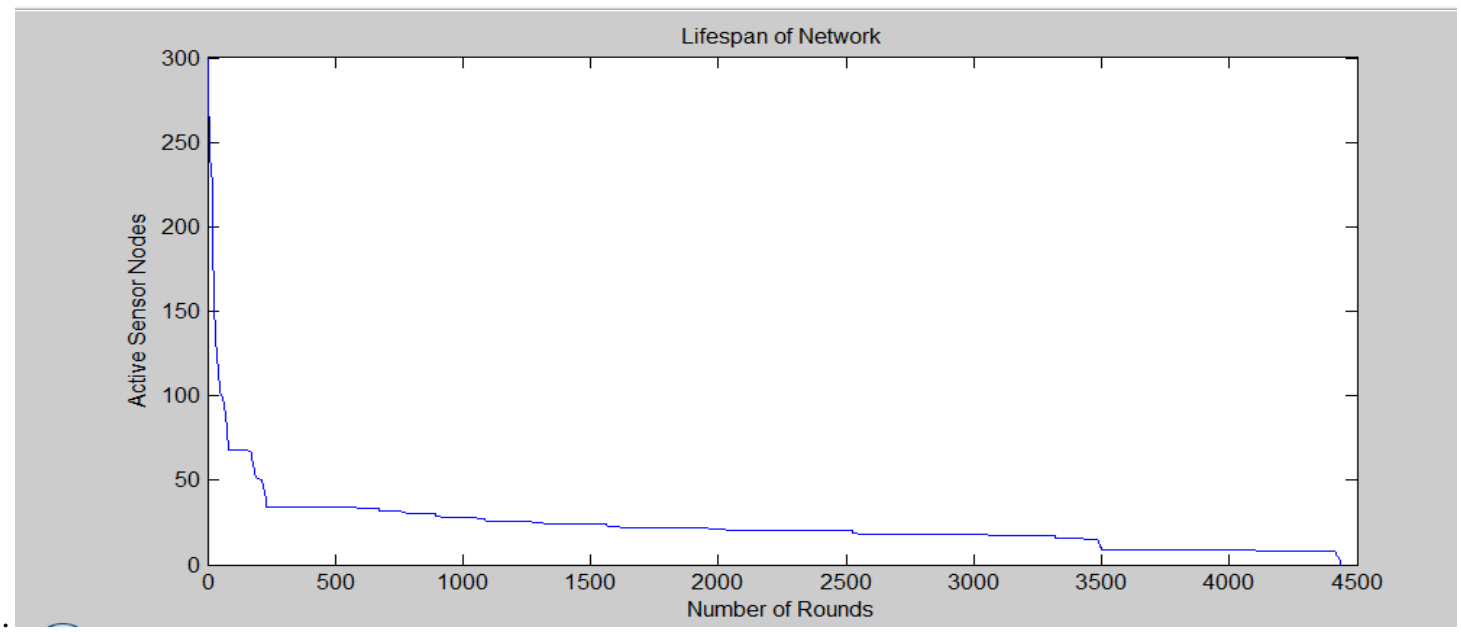

Figure 17: Lifespan of hierarchical (18 Clusters) Network of 3000m by 60m R/W

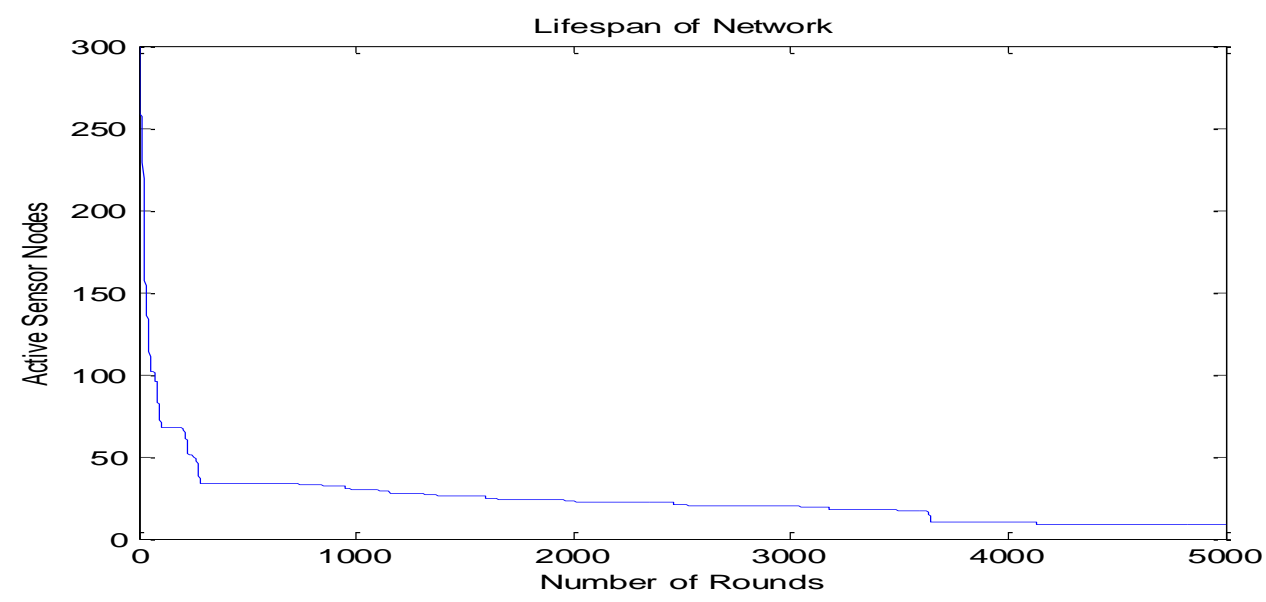

Figure 18: Lifespan of hierarchical (18 Clusters) Network of $2700 \mathrm{~m}$ by $45 \mathrm{~m} \mathrm{R} / \mathrm{W}$

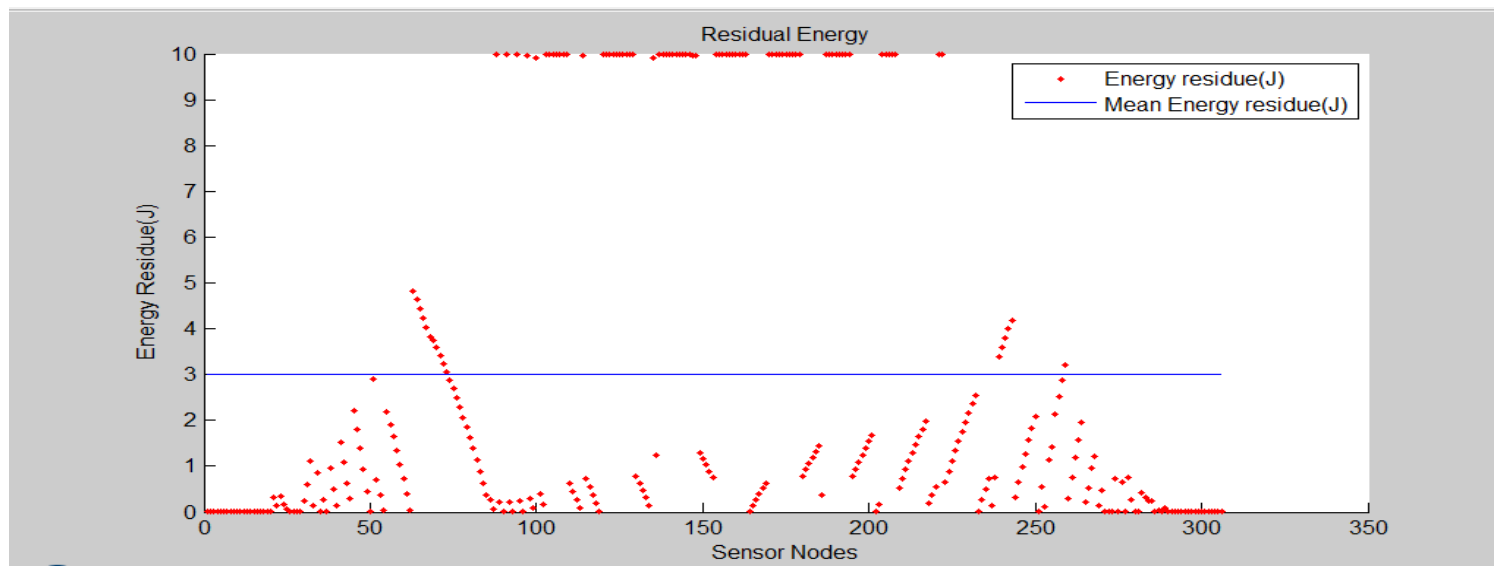

Figure 19: Residual Energy of hierarchical (18 Clusters) Network of 3000m by 60m R/W 


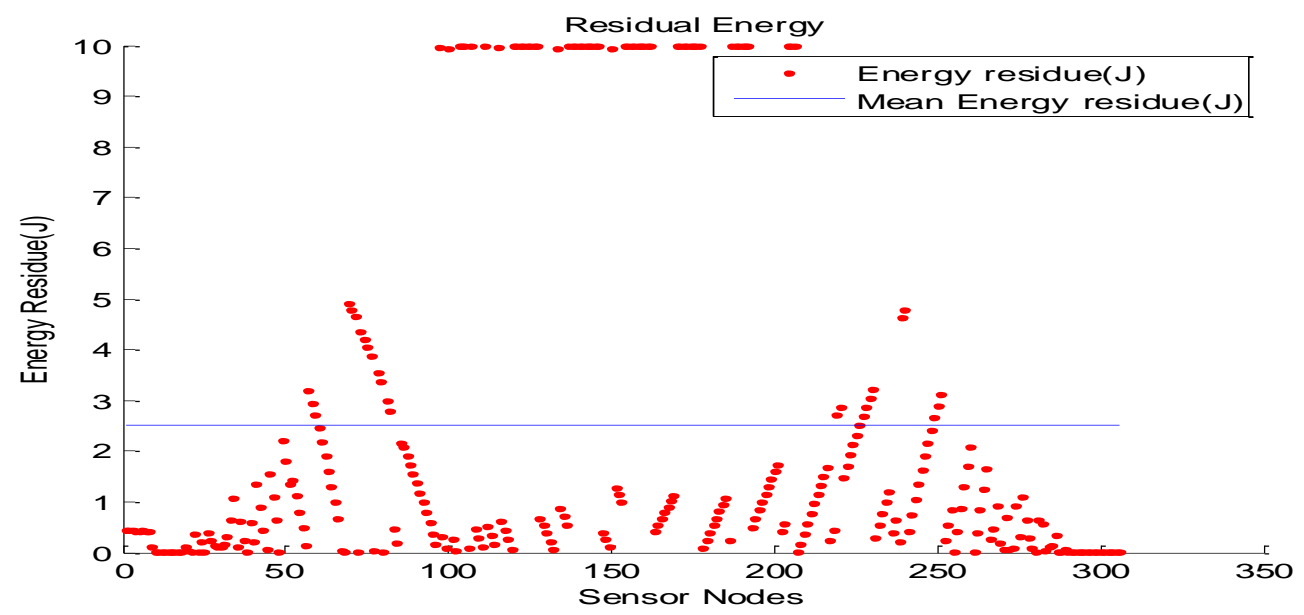

Figure 20: Residual Energy of hierarchical (18 Clusters) Network of $2700 \mathrm{~m}$ by $45 \mathrm{~m} \mathrm{R} / \mathrm{W}$

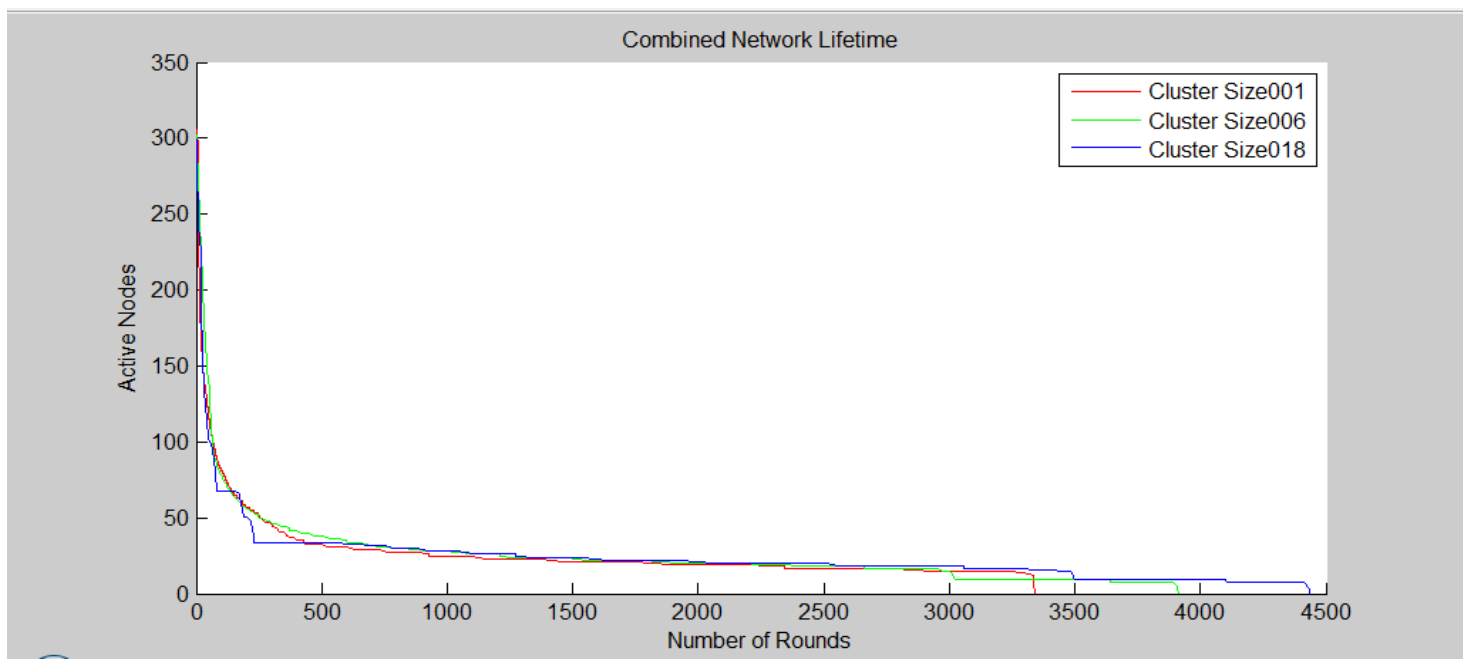

Figure 21: Combined Network Lifetime of $3000 \mathrm{~m}$ by $60 \mathrm{~m}$ R/W.

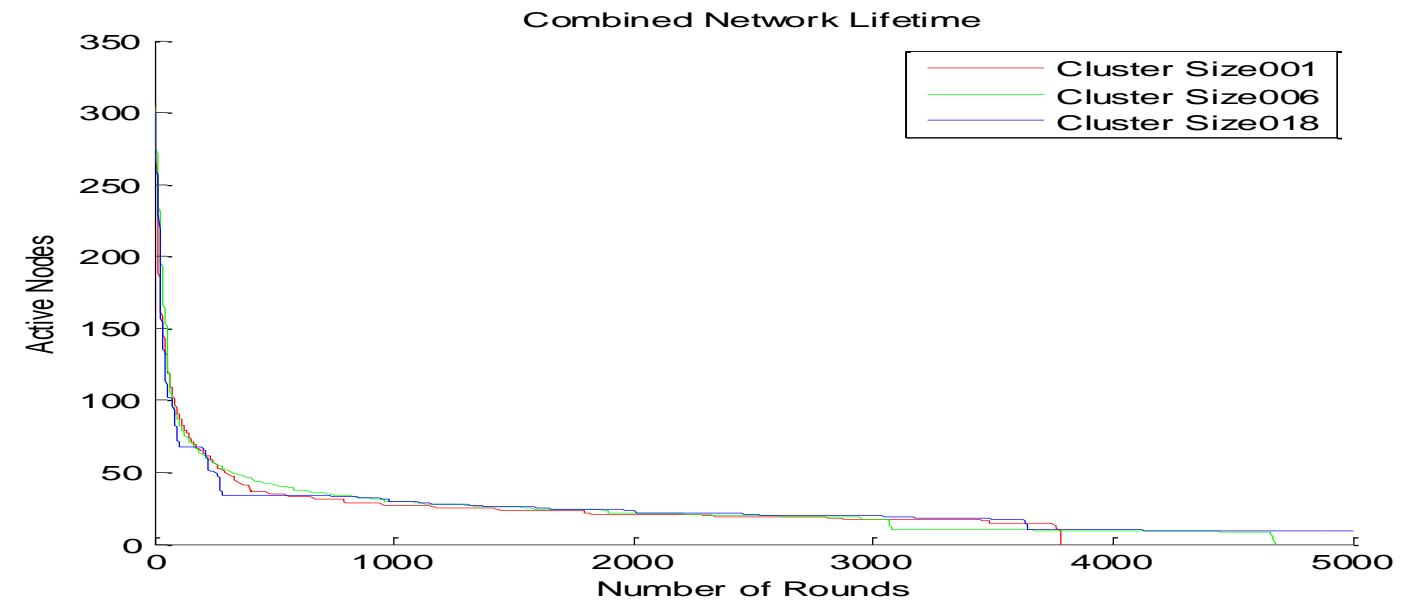

Figure 22: Combined Network Lifetime of $2700 \mathrm{~m}$ by $45 \mathrm{~m} \mathrm{R} / \mathrm{W}$ 


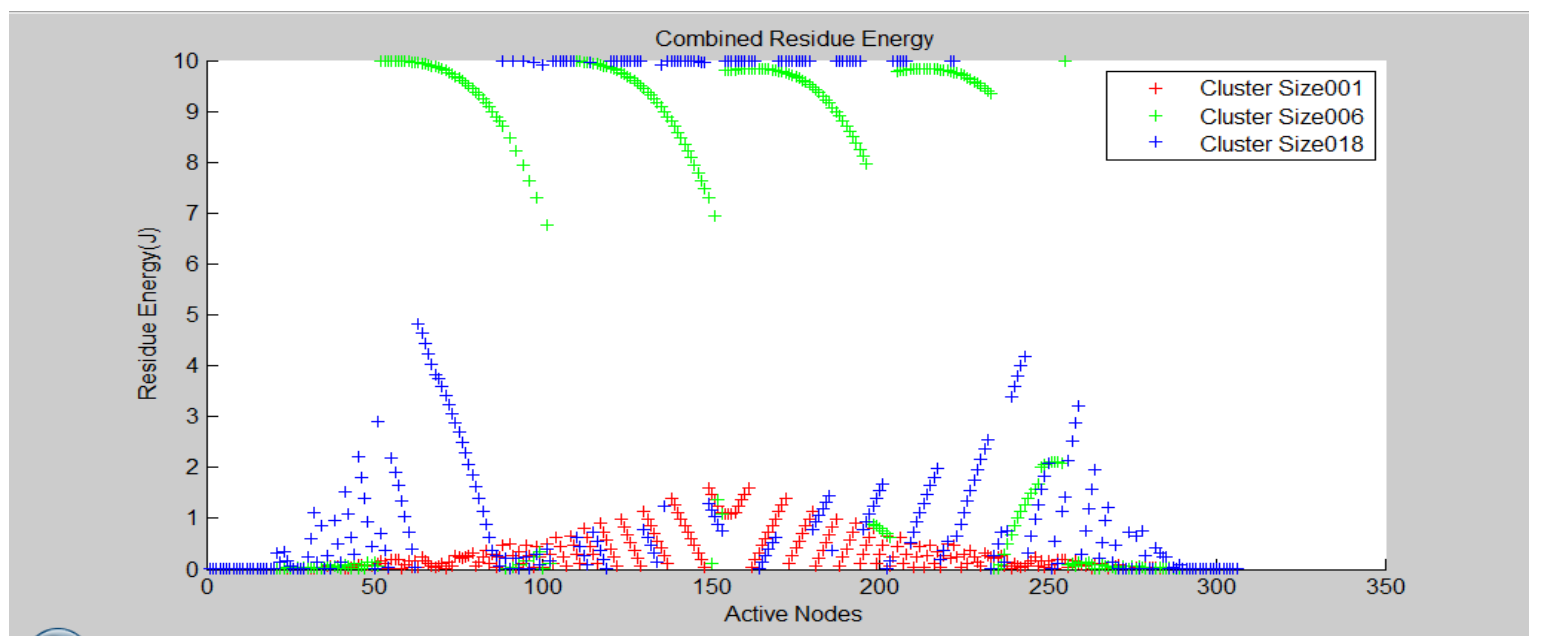

Figure 23: Combined Residue Energy of 3000m by $60 \mathrm{~m} \mathrm{R} / \mathrm{W}$

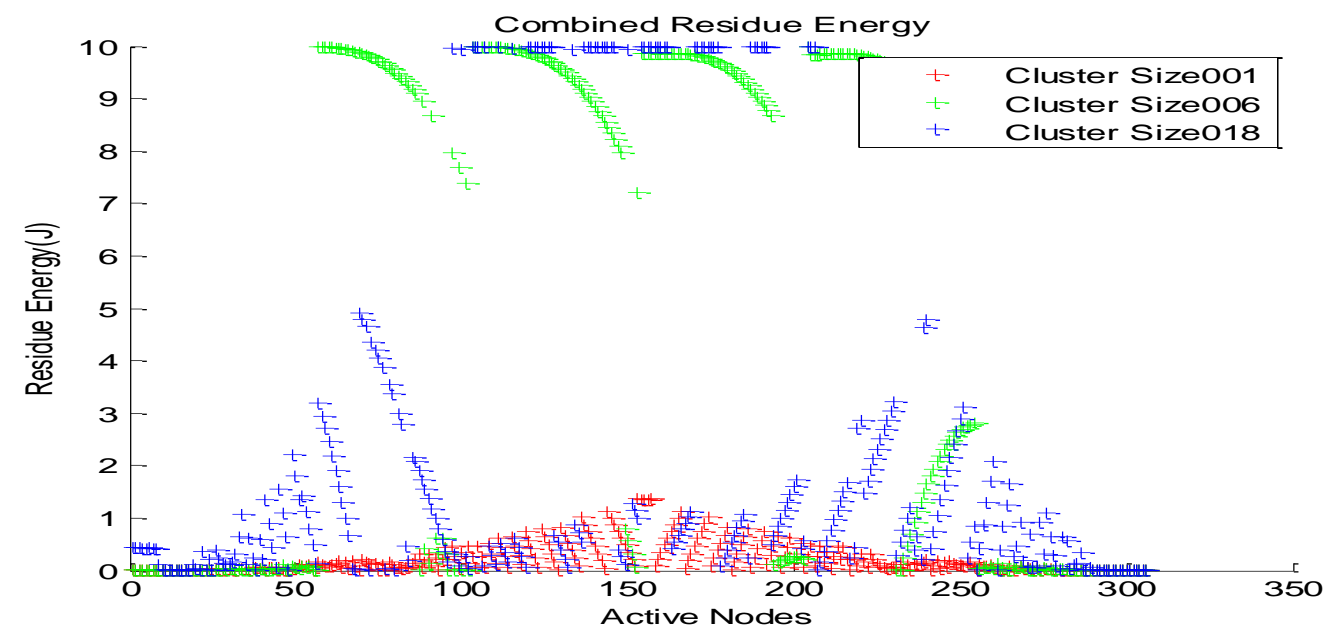

Figure 24: Combined Residue Energy of 2700m by $45 \mathrm{~m}$ R/W

\section{B. DISCUSSION OF RESULTS}

It had been revealed and equally justified in this work that hierarchical routing protocol among other protocols offered a better performance in improving the life-span of WSNs. Hierarchical routing reduces the number of nodes involved in transmission which consequently reduces communication over-head [7], [12].The performances of the hierarchical routing protocol in this work evaluated based on network life-span proved that hierarchical routing of data to the Base Station enhances the lifespan of WSNs. Thus, making clustering routing protocol the most suitable and compactable for WSNs [7]. A total of 306 nodes were evenly distributed along the perimeter of the selected Aircraft Runways with dimensions; 3000m by 60m [19] and 2700m by 45m [20] with the Sink node located at $(-30,-10)$ coordinates. The initial energy level of all nodes were set at $10 \mathrm{~J}$,transmitter electronics $\mathrm{E}_{\mathrm{TX}}$ and receiver electronics $\mathrm{E}_{\mathrm{RX}}$ set to $50 \mathrm{~nJ} / \mathrm{bit}$, Transmitter power amplifier electronics $\in_{a m p}$ set to $100 \mathrm{PJ} / \mathrm{bit} / \mathrm{m}^{2}$ to achieve an acceptable energy per bit over noise spectral density [18] and the packet size of the sensor data set to 2000 bits. The first order radio model equation proposed in [18] was used to predict the minimal transmission energy level for Cluster head selection, data aggregation and transmission phase for 5000 rounds of cluster sizes 1, 6 and 18. In each cluster, $\mathrm{CH}$ aggregates the data received from other sensor nodes, fuses with its own data and transmit 
through the least path to the Sink. Every communication made incurs energy loss for every node, thus, Cluster Head rotation was adopted to prolong the lifespan of the network. Figure 9 and 10 illustrates the lifespan of the non-hierarchical deployment of wireless sensor nodes on the selected Aircraft Runways. More data are being processed and routed to the Base Station through the node assigned for routing in each round since the network is a replica of single cluster deployment. The lifespan of the networks lasted for 3375 and 3750 rounds of simulation respectively for the selected Aircraft Runways. The mean energy residues are 0.3J and 0.22J respectively as illustrated on figures 11 and 12. The results displayed on figures 13 and 14 illustrate the lifespan of 6 cluster hierarchical configuration which enhances a reduction in communication overhead at the Cluster Head. The sampled networks lasted for 3912 and 4660 rounds of simulation while the mean energy residues are 5.2J and 4.8J respectively as illustrated on figures 15 and 16. Figures 17 and 18 displayed the lifespan of 18-cluster hierarchical network configuration being the maximum possible cluster in the deployed samples. The increased number of cluster greatly reduces the size of data routed by each Cluster Head to the Base Station, since a reduced number of nodes send their data to the Cluster Head where the data is being aggregated and routed to the BS. The significant reduction in data transmitted to the Base Station enhances the lifespan of the network as it lasted for 4434 rounds of simulation and exceeds the pre-estimated 5000 rounds while the mean energy residues are $3.0 \mathrm{~J}$ and $2.5 \mathrm{~J}$ as displayed on figures 19 and 20. Considering the mean residue energy of the 6-cluster and 18-cluster hierarchical configurations, and comparing with the nonhierarchical configuration, it was observed that the values displayed; average value of reserved energy otherwise regarded as mean energy residue after simulation rounds in the hierarchical configurations far exceed the non-hierarchical. Table 2 and 3 illustrates the performance of each network in terms of active sensor nodes versus number of simulation rounds (Lifespan) based on the preestimated 5000 simulation rounds. The displayed mean energy residue in the network is the average energy content of nodes when the network could no longer establish transmission to the Base Station.

Table 2: NETWORK CONFIGURATION, NETWORK LIFESPAN AND MEAN ENERGY RESIDUE FOR 3000m by 60m R/W

$\begin{array}{lll}\text { Network } & \text { Network } & \text { Mean Energy } \\ \text { Configuration } & \text { Life-span } & \text { Residue (J) }\end{array}$

\begin{tabular}{|c|c|c|}
\hline Non-hierarchical & 3375 & 0.3 \\
\hline 6-Cluster hierarchy & 3912 & 5.2 \\
\hline
\end{tabular}
18-Cluster hierarchy
4434
3.0

Table 3: NETWORK CONFIGURATION, NETWORK LIFESPAN AND MEAN ENERGY RESIDUE FOR 2700m by 45m R/W

\begin{tabular}{llc}
\hline $\begin{array}{l}\text { Network } \\
\text { Configuration }\end{array}$ & $\begin{array}{l}\text { Network } \\
\text { Life-span }\end{array}$ & $\begin{array}{l}\text { Mean Energy } \\
\text { Residue (J) }\end{array}$ \\
\hline Non-hierarchical & 3750 & 0.22 \\
6-Cluster hierarchy & 4660 & 4.8 \\
18-Cluster hierarchy & $>5000$ & 2.5 \\
\hline
\end{tabular}


Comparing the simulation results of the sampled runways as illustrated on tables 2 and 3 , all simulation parameters being constant, the only varied parameter being the dimension of the runways. The effect of this enhances the performance of the model on the $2700 \mathrm{~m}$ by $45 \mathrm{~m}$ runway compared with the $3000 \mathrm{~m}$ by $60 \mathrm{~m}$ dimension in terms of the simulation rounds. Because of the increase in the dimension of the $3000 \mathrm{~m}$ by $60 \mathrm{~m}$ runway compared with $2700 \mathrm{~m}$ by $45 \mathrm{~m}$, this consequently increases the distance demand on wireless sensor nodes to transmit data. Thus, the increase in distance increases the energy needed to transmit from source to destination.

\section{CONCLUSION}

In this work, an Energy-efficient Wireless Sensor Network for Aircraft Runway was modeled. Energy-efficient hierarchical routing technique where Cluster Heads are selected based on residual energy and proximity to the Base Station was adopted. Equally, rotation of Cluster Head role and optimization of Cluster Heads selection based on the prediction of energy used for transmission in every transmission round and proximity to BS were considered. Analysis of hierarchical routing technique in transmitting data to the Base Station was conducted and the result lends credence to the fact that hierarchical routing technique offers a better approach to elongate the network lifetime. In the routing protocol, the networks were formed into different cluster size to reveal how it could affect the network life-time. With energy awareness being the core interest, the proposed routing protocol which uses the prediction of least transmission energy through the shortest distance to send data to the Base Station proves that it offered more energy savings and consequently increases the lifespan of the deployed network. From the simulation result, the deployment of 306 wireless sensor nodes along the Runway perimeters with dimension $3000 \mathrm{~m}$ by $60 \mathrm{~m}$ and $2700 \mathrm{~m}$ by $45 \mathrm{~m}$, the Sink node being located outside the perimeter at $(-30,-10)$ coordinates, for the non-hierarchical and hierarchical deployments showed that the hierarchical deployment performances exceed the non-hierarchical and the 18 hierarchical deployment (the highest possible cluster size) yielded the longest network lifespan.

\section{RECOMENDATIONS AND FUTURE WORK}

The increasing challenge of energy resources in Wireless Sensor Networks particularly when deployed in regions with limited access could pose a constraint to its usage as constant recharging and replacement is not a viable option. The following recommendations are made: The model of WSNs in this work can be applied for monitoring any size of Aircraft Runway and similar perimeter as only a slight modification will be needed. Future improvement on the developed model is also recommended to cater for other challenges such as: Scalability, quality of service, network coverage and security. The variations in mean energy residue metric also require further studies.

\section{REFERENCES}

[1] Zahra R and Shima M (2012). "Energy saving in wireless sensor networks.” International Journal of Computer Science and Engineering Survey (1YCSES), Vol 3. N0.1, Page 24.

[2] Kazem S. and Daniel M., (2007). “Wireless Sensor Networks: Technology, protocols and Application.” Hoboken, New Jersey. John Wiley and sons Inc. [3] Abbasi A.A. and Younis M. (2007). "A survey on clustering algorithms for Wireless Sensor Networks". Compute. Commun. 30, 2826-2841

[4] Bhaskar , Krishnamachari (2005). "An introduction to wireless sensor network". A tutorial Presented at the second international conference on intelligent sensing and information Processing (ICISIP), Chennai, India.

[5] Soro, S. and Heinzelman, W.B. (2009). "Cluster head election techniques for coverage preservation in Wireless Sensor Networks". Ad Hoc Networks. Vol7, Pages 955-972.

[6] Giuseppe Anastasi, Marco Conti, Mario Di Francesco and Andrea Passarella (2009). "Energy Conservation in wireless sensor network: A survey". Elseivier Journal Pages 537-539.

[7] Heinzelman W.R., Chandrakasan A., and Balakrishan H. (2000). "Energy- Efficient Communication protocol for Wireless Micro-sensor Networks". In Proceeding of the 33rd Hawaii International Conference on System Sciences, Pages1-10.

[8] Sangho, Yi and Junyoung, Heo (2007). "PEACH: Power-Efficient and Adaptive Clustering Hierarchy protocol for wireless sensor networks". Journal of computer communication, Vol 30, Issue 14-15. PP 2842-2582.doi> 10.1016/j.comcom.2007.05.034

[9] Younis , O. and Fahmy, S. (2004). "Hybrid energy- efficient distributed clustering approach for Ad-hoc sensor networks". IEEE Trans. On Mobile Computing. 3, 366-379.

[10] Abdulla, I. Alhasanat., Ahmad Ali A, Khitan, M. A. and Aws, Alqaisi (2015). "Data Gathering in Wireless Sensor Networks using intermediate nodes". International Journal of Computer Networks and Communication (IJCNC).Vol7.No.1, Pages 114-117. 
[11] Haneef, M. and Zhongliang, D. (2012). "Design challenges and comparative analysis of Cluster Based Routing Protocols used in Wireless Sensor Networks for improving network Lifetime”. Journal of Advanced Information and Science Service. Vol 4. Pages 450-459

[12] Liu X.X. (2012). “A Survey on Clustering Routing Protocols in Wireless Sensor Networks”. Sensor (Basel) doi: 10.3390/s120811113.

[13] Sahoo B.P.S., Deepak, Puthal and Satyajit, Rath (2014). "An Energy Efficient Optimal Routing Method for Wireless Sensor Network". ARPN Journal of Science and Technology. Vol 4, No 10, Page 559.

[14] Surender, K., \& Manish, P. (2013). "Energy Efficient (EECP) Clustering Protocol for Heterogeneous Wireless Sensor Network". International journal of Advanced Research in Computer Science and Software Engineering Vol 3, Issue 7. Pages 1448-1453.

[15] Taruna S., Kumawat, R., \& Purohit G.N. (2012). "Multi-Hop Clustering Protocol using Gateway Nodes in Wireless Sensor Network". International Journal of Wireless and Mobile Network (IJWMN) Vol 4, No.4.

[16] Abidoye, Ademola P. \& Nureni A. Azeez (2011). "A Novel clustering Algorithm for energy-efficiency wireless sensor networks". Doi:10.4236/wsn.2011.39032 published online September2011http://www.scrRP.org/journal/wsn).

[17] Taruna, S. and Megha, R.T. (2013). "Event Driven Hierarchical Cluster based Routing Protocol for Wireless Sensor Network". International journal of Advanced Research in Computer Science and Software Engineering. Vol 3, Issue 4, Pages 549-556.

[18] Heinzelman W.B., Chandrakasan A. and Balakrishan H. (2002). “An Application Specific Protocol Architecture for Wireless Micro- sensor Networks. IEEE Transactions on Wireless Communications, Vol 1. No 4, Pages 660-670.

[19] Port Harcourt International Airport Aircraft Runway. Retrieved from http://www.portharcourtInternationalairportrunway/dimension_mod.html. Accessed on 19/09/2017.

[20] Sam Mbakwe Airport Aircraft Runway. Retrieved from http://www.sammbakweairportrunway/dimension_mod.html.Accessed on19/09/2017.

\section{AUTHORS}

First Author - Oluwadara J. Odeyinka, Department of Electrical and Electronic Engineering, Federal University of Technology, Owerri, Nigeria. Email: odeyinkaoj@gmail.com

Second Author - Engr. Prof. Michael C. Ndinechi (MNSE). Director, ICT Centre, Federal University of Technology, Owerri. Email: mondinechi@gmail.com,michael.ndinechi@futo.edu.ng

Third Author - Engr. Dr. Onyebuchi C. Nosiri, Department of Electrical and Electronic Engineering, Federal University of Technology, Owerri, Nigeria. Email: buchinosiri@gmail.com 